\title{
Interactions between fine-grained sediment delivery, river bed deposition and salmonid spawning success
}

\author{
IAN PATTISON ${ }^{1}$, DAVID A. SEAR ${ }^{2}$, ADRIAN L COLLINS ${ }^{3}$, J. IWAN JONES ${ }^{4}$ \\ \& PAMELA S NADEN ${ }^{5}$ \\ 1 School of Civil and Building Engineering, University of Loughborough, Loughborough, LE11 3TU, UK \\ i.pattison@,lboro.ac.uk \\ 2 Geography and Environment, University of Southampton, Highfield, Southampton, S017 1BJ, UK \\ 3 Department of Sustainable Soils and Grassland Systems, Rothamsted Research-North Wyke, Okehampton, Devon \\ EX20 2SB, UK \\ 4 School of Biological and Chemical Sciences, Queen Mary University of London, Mile End Road, London E1 4NS, UK \\ 5 Centre for Ecology and Hydrology, Crowmarsh Gifford, Wallingford, Oxfordshire, UK
}

\begin{abstract}
Salmonids clean river bed gravels to lay their eggs. However, during the incubation period fine sediment infiltrates the bed. This has been found to limit the success of salmonid spawning, as fine sediment reduces gravel permeability resulting in intra-gravel flow velocities and $\mathrm{O}_{2}$ concentrations decreasing. The success of salmonid spawning is therefore a function of the coincidence of fine sediment delivery and the development of the salmonid eggs. The presence of fine sediment also exerts sub-lethal effects on the rate of egg development with a negative feedback slowing and extending the incubation process meaning the eggs are in the gravels for longer and susceptible to more potential sediment delivery events. The SIDO (Sediment Intrusion and Dissolved Oxygen)-UK model is a physically-based numerical model which simulates the effect of fine sediment deposition on the abiotic characteristics of the salmonid redd, along with the consequences for egg development and survival. This model is used to investigate the interactions and feedbacks between the timing and concentrations of suspended sediment delivery events, and the deposition of fine sediment within the gravel bed, and the consequences of this on the rate of egg development and survival. The model simulations suggest that egg survival is highly sensitive to suspended sediment concentrations, particularly to changes in the supply rate of sand particles. The magnitude, frequency and specific timing of sediment delivery events effects egg survival rates. The modelling framework is also used to investigate the impact of the rate of gravel infilling by sediment. The hypotheses of continual, discrete event and non-linear decline in the rate of infilling are investigated.
\end{abstract}

Key words fine sediment; deposition; salmonids; numerical modelling

\section{INTRODUCTION}

The enhanced erosion and delivery of fine sediment from a wide range of sources, e.g. agricultural fields, urban areas and river banks, has several negative impacts upon river systems. Firstly, fine sediment aggradation may lead to increased flood risk as the channel capacity reduces (Remo et al., 2009). Secondly, fine sediment is often associated with contaminants, such as nutrients and heavy metals (Salomons and Forstner, 1984). This may result in eutrophication and water quality degradation, which has implications for aquatic ecology. The EU Water Framework Directive has set the goal of achieving good ecological status by 2015 but currently only $\sim 27 \%$ of UK rivers will meet this target. Thirdly, fine sediment has direct impacts on aquatic ecology including macroinvertebrates (Jones et al., 2012a), macrophytes (Jones et al., 2012b), diatoms (Jones et al., 2014) and fish (Kemp et al., 2011). Field observations have shown that fine sediment has consequences for all life stages of salmonids, with adult salmonids visual foraging behaviour changing due to high water turbidity. However, Cunjak et al. (1998) argue that it is the fish eggs that are most severely affected, which has wide reaching impacts for sustainable fish populations. As fish eggs are immobile, they are susceptible to the fine sediment delivered to the reach where they are laid. The adult salmon cleans the gravels before laying the eggs to produce a favourable initial incubating habitat (also known as a redd). However, from this time until the alevin hatch and emerge from the gravels, the eggs are sensitive to fine sediment delivery. Several studies (Chapman, 1988; Sear et al., 2008) have found that sediment infiltration into the redd reduces the spawning success rate. There have been several hypotheses put forward to explain this observation: (a) physical blockage of intragravel pores, where the reduction in gravel porosity and permeability results in the reduction in intragravel flow velocities and therefore a decrease in the supply of oxygen rich water to the egg zone; (b) sediment oxygen consumption, where the organic matter associated 
with the finer size classes decomposes using oxygen, meaning it becomes limiting for egg survival, and; (c) egg membrane micropores are blocked (Greig et al., 2005) limiting metabolic exchanges. The success of salmonid spawning is therefore a function of the coincidence of fine sediment delivery and the development of the salmonid eggs during the incubation period. The specific timing and magnitude of sediment delivery is thought to be key to this linkage.

\section{METHODOLOGY}

This paper uses a numerical model, SIDO-UK (Sediment Intrusion and Dissolved Oxygen) to test the sensitivity of salmonid egg survival rates to the input sedigraph characteristics. This includes the quantity of fine sediment (sand, silt and clay fractions) supplied to the reach and how this affects different species of salmonids: Atlantic Salmon and Brown Trout.

\section{SIDO-UK MODEL}

SIDO-UK is a physically-based numerical model which simulates the transport of water, fine sediment and oxygen through the redd habitat where salmonid eggs incubate. The model structure consists of a channel reach, represented by cross sections, with a salmonid redd located within it (Fig. 1). A natural redd is a complex geomorphological bed form, so its structure is simplified within SIDO-UK by reducing its 3D structure into a $2 \mathrm{D}$ grid due to the symmetry seen within the feature. The reach-scale component of the model calculates the average daily channel hydraulic characteristics for input into the sub-daily redd habitat component. The rate of fines infiltrating the redd is assumed to be directly correlated to the near-bed concentration of suspended sediment. Fine sediment accumulates within the redd, filling from the base of the redd upwards. The percentage of the redd by volume that is infilled is reported. The particle size distribution of the gravel matrix and the ingressing fine sediment control the overall porosity of the area around the incubating salmonid eggs. This determines the intra-gravel flow velocity via Darcy's law, and the supply of oxygenated water is represented through the inclusion of the process of convection. SIDO incorporates the model of Theurer and Theurer (1986) for the oxygen consumption term, which includes both sediment and egg components. Further details of the SIDO model process representation can be found in Alonso et al. (1996) and Pattison et al. (submitted).

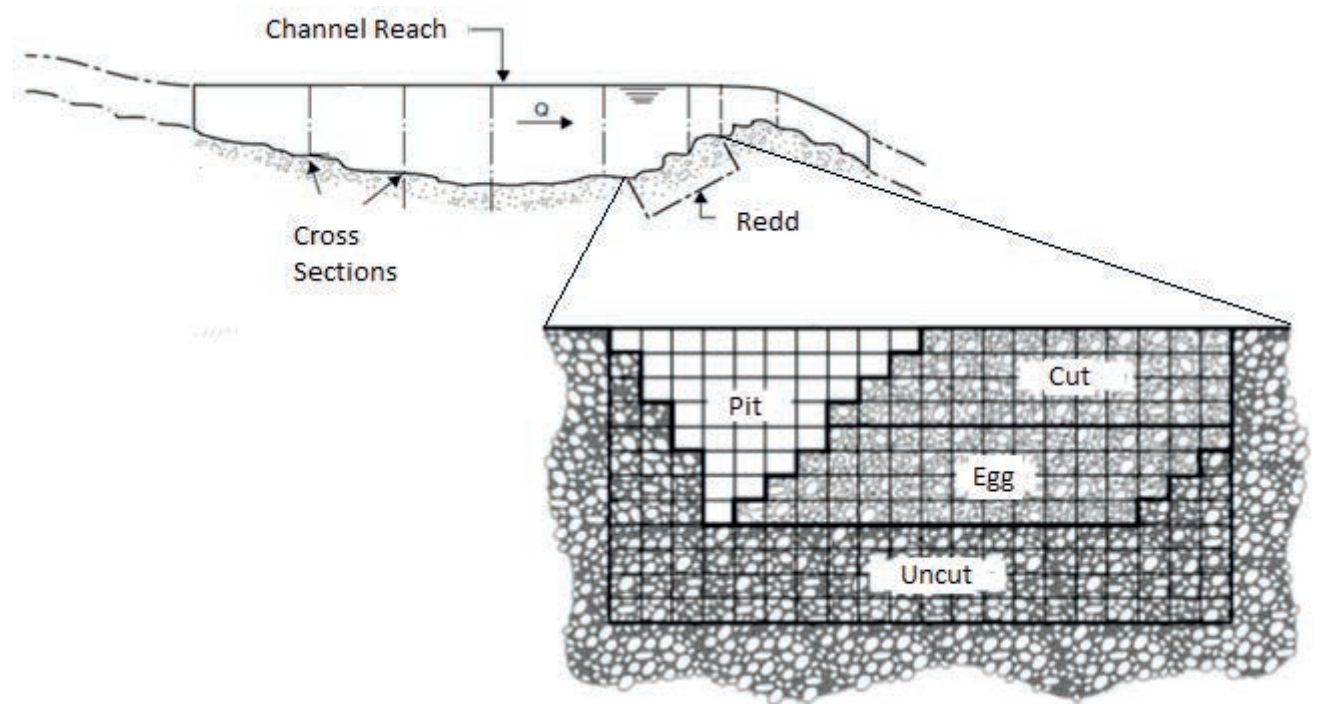

Fig. 1 The representation of a channel reach by the SIDO-UK model (modified from Alonso et al., 1988).

\section{RIVER ITHON CASE STUDY}

The River Ithon is a 3rd-order tributary of the River Wye (Catchment area $\left.=32 \mathrm{~km}^{2}\right)$, and is an example of an upland freshet river. The straight $75-\mathrm{m}$ modelled reach in this river consists of eight 
cross-sections. The period of data collection (153 days) in the winter of 2002-2003 was characterised by a high average discharge $\left(13.02 \mathrm{~m}^{3} \mathrm{~s}^{-1}\right)$ and suspended sediment load $\left(81.4 \mathrm{mg} \mathrm{L}^{-1}\right)$ (Fig. 2), comprising 23\% clay, $56 \%$ silt and $21 \%$ sand (Greig et al., 2007). Suspended sediment concentrations were measured using a Partech IR400 turbidity probe (NTU) located $0.05 \mathrm{~m}$ above the stream bed and locally calibrated against daily pump samples of suspended sediment concentration. The Ithon experienced a series of storm events resulting in high river flows and associated suspended sediment concentrations from Day 59 until Day 90. The maximum discharge of $129 \mathrm{~m}^{3} \mathrm{~s}^{-1}$ occurred on Day 66 and the maximum suspended sediment concentration of $798 \mathrm{mg} \mathrm{L}^{-1}$ on Day 59. The timing of these events coincided with the incubation of the salmonid eggs within the channel reach.

(a)

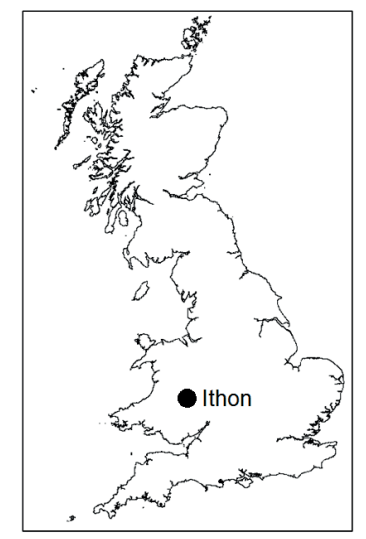

(b)

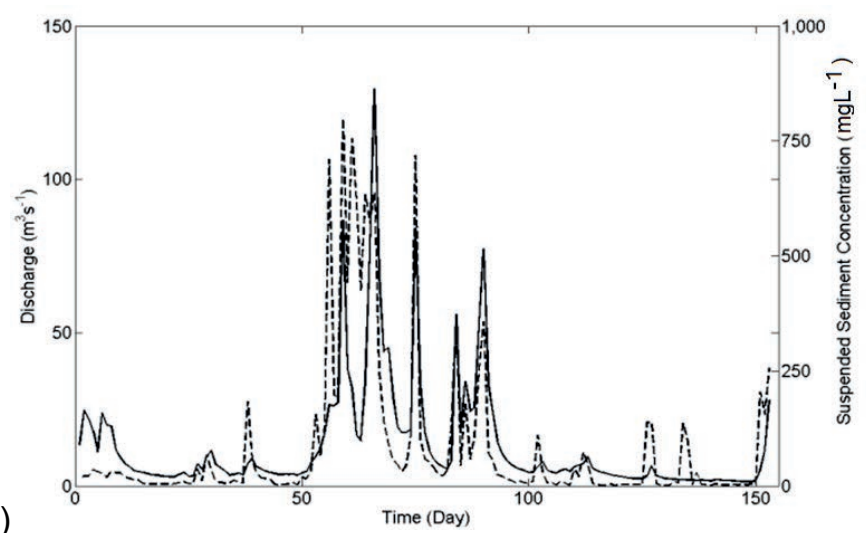

Fig. 2 (a) Location map showing River Ithon; (b) Observed discharge (solid) and daily suspended sediment concentrations (dashed) during winter 2002/2003 for the River Ithon study reach.

\section{RESULTS}

\section{Model calibration}

The SIDO-UK model was validated using observations of fine sediment accumulation volumes within artificial redds collected as part of the Greig et al. (2007) study. The calibration using the $\mathrm{CBABJ}$ parameter that controls the near bed concentration of fine sediment, which redd ingressing is directly related to, was optimised for the final accumulated infilled sediment volume. A sensitivity analysis of the model to this CBADJ parameter found ingressing was highly sensitive to changes in the CBADJ value, as expected. Intra-gravel flow velocity was also highly sensitive as this is controlled by the porosity and permeability of the gravel matrix which became clogged up with ingressing fine sediment. However, the dissolved oxygen concentration was less sensitive to changes in the CBADJ parameter as this is dependent on other controlling factors such as the sediment oxygen demand of the fine sediment and the egg consumption rate, as well as water temperature and discharge. A low parameter value for CBADJ was needed for the observed period for the River Ithon, as the period was characterised by high suspended sediment concentrations and, therefore, near bed concentration did not need to be "enhanced" by this calibration parameter.

The model performed well with the final observed accumulated volume ranging from $21.6 \%$ to $24.5 \%$ (Fig. 3). The calibrated model simulated a final accumulated volume of $22.5 \%$ which was within the range of the observations and had a mean percentage error of $2.5 \%$. However, from Fig. 3 it is clear that the model performed less well for periods of lower levels of accumulation. This is probably a model artefact and a function of the grid resolution representing the redd zone. It is encouraging that accumulation within the redd zone started on Day 59, which was the first day of significant suspended sediment load.

The baseline (calibrated) model results in terms of sediment infilling, abiotic conditions (intragravel flow velocity and dissolved oxygen) and biotic response in terms of salmonid egg survival are shown in Fig. 4. Sediment infilling started on Day 59 with $7 \%$ of the pore space filled with fine sediment. This increased during the 30 -day storm period to $22.5 \%$ on Day 90 , which remained the 
same until the eggs hatch on Day 107. Further intrusion of the redd by fine sediment occured between hatch and emergence, with a total accumulated volume of $28.3 \%$ at the end of the model simulation period.

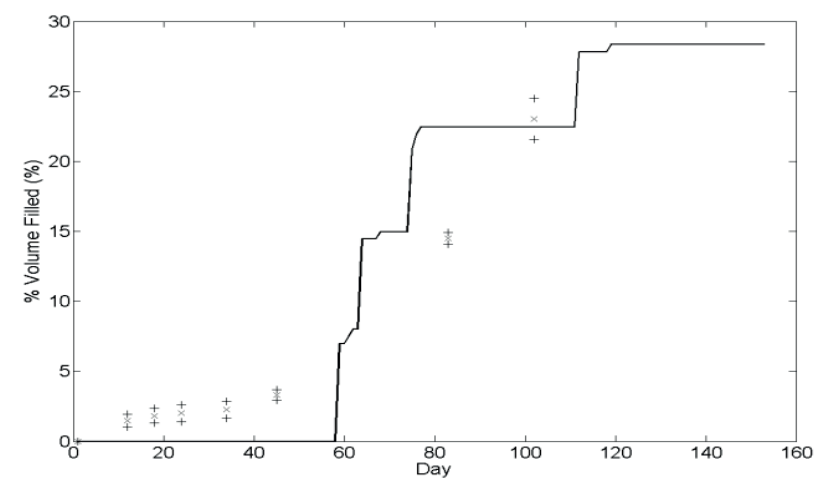

Fig. 3 Model calibration using sediment accumulation data for the River Ithon study reach.

a)

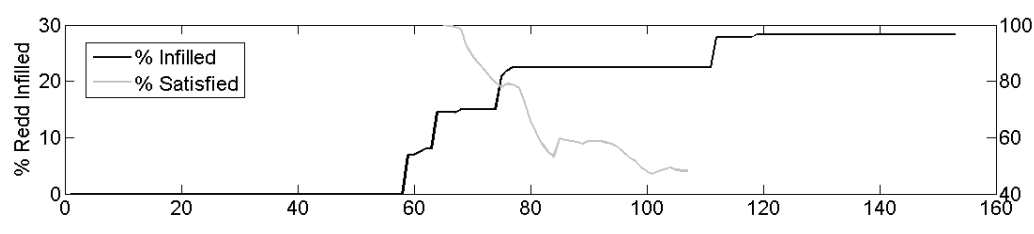

b)
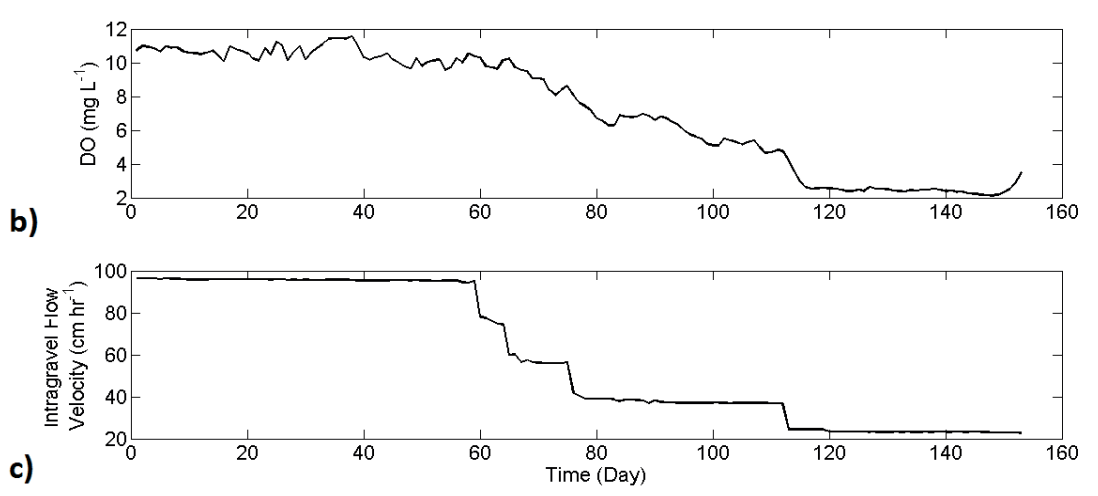

Fig. 4 Baseline SIDO-UK model results for: (a) sediment ingressing/percentage eggs satisfied by oxygen available; (b) DO, and; (c) intra-gravel flow velocity.

The intra-gravel flow velocity was highly sensitive to fine sediment infilling within the redd gravel matrix. The initial simulated intra-gravel flow velocity was about $95 \mathrm{~cm} \mathrm{~h}^{-1}$. This decreased to $77 \mathrm{~cm} \mathrm{~h}^{-1}$ on Day 59, when fine sediment infilling started to occur. A further decline of $40 \mathrm{~cm} \mathrm{~h}^{-1}$ occurred during the storm period to a value of $38 \mathrm{~cm} \mathrm{~h}^{-1}$ on Day 90 . The intra-gravel flow velocity on the day of salmonid hatch was $36 \mathrm{~cm} \mathrm{~h}^{-1}$.

The dissolved oxygen concentration within the egg zone fluctuated around $10-11 \mathrm{mg} \mathrm{L}^{-1}$ from the beginning of the simulation period until major sediment infilling occurs (just after Day 60). The decline in dissolved oxygen concentration was gradual as intra-gravel pores in the redd became progressively clogged with fine sediment. By the day of salmonid hatch, concentrations were $5.4 \mathrm{mg} \mathrm{L}^{-1}$, and concentrations declined to a low of $\sim 2 \mathrm{mg} \mathrm{L}^{-1}$ at the end of the simulation. The result of fine sediment infiltrating into the redd zone and degrading the quality of the spawning habitat around the incubating eggs was that modelled egg survival to hatch was $48 \%$.

\section{Impact of changing sediment inputs}

The sensitivity of the SIDO-UK model to sediment input was tested by both increasing and decreasing the suspended sediment (sand, silt and clay) loads by different percentages: $1 \%, 2.5 \%$, 
$5 \%, 10 \%, 25 \%, 50 \%, 75 \%$ and $100 \%$, relative to the measured value. The effect on average abiotic conditions within the redd zone was assessed through the consideration of: (a) the \% redd infilled; (b) intra-gravel flow velocity, and; (c) dissolved oxygen concentration. Ultimately, the conditions on the day of hatch were considered along with how the sediment scenario affected modelled egg survival rates for two salmonid species, namely Atlantic Salmon and Brown Trout.

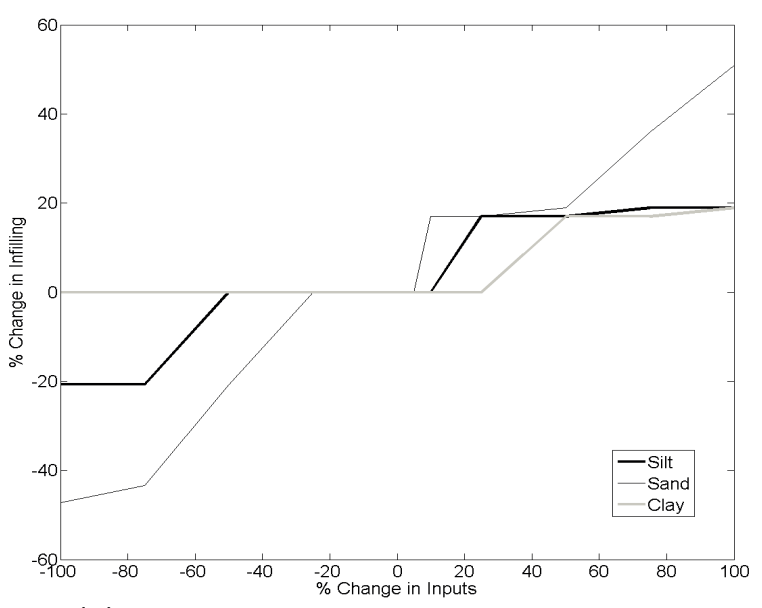

(a) \% Redd infilled with fine sediment

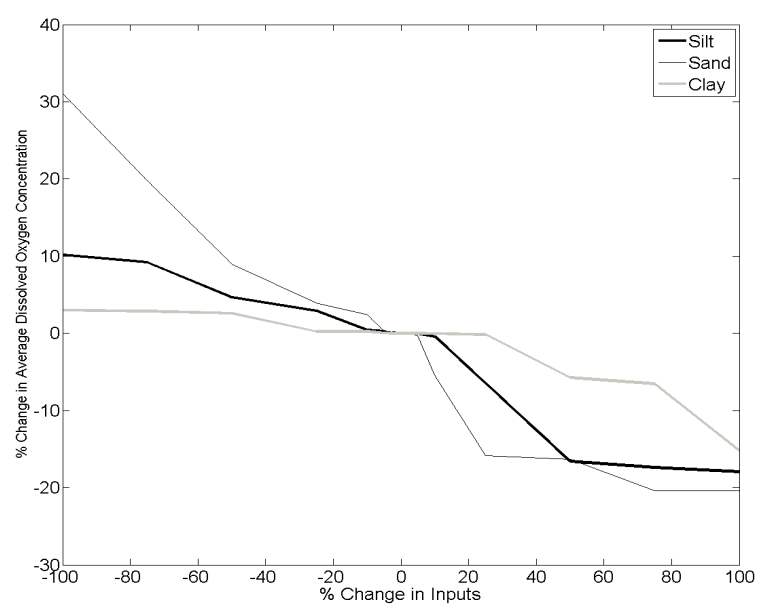

(c) Mean dissolved oxygen concentration

Fig. 5 Impact of changing sediment loads on: (a) infilling; (b) intra-gravel flow velocities; and (c) dissolved oxygen concentrations.

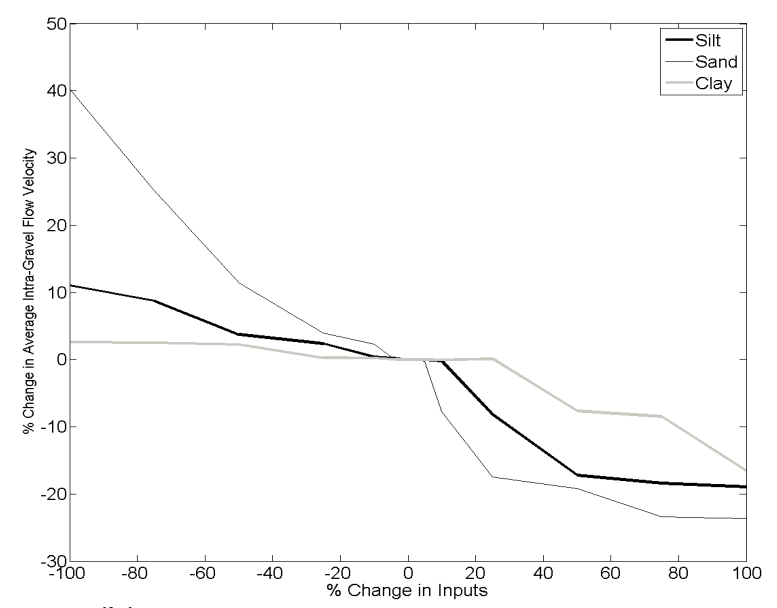

(b) Mean intra-gravel flow velocity

The quantity of fine sediment infiltrating into the gravel matrix and clogging the redd changed with the amount of fine sediment being supplied to the study reach. An increase in fine sediment inputs caused more accumulation, with the largest changes being seen for sand. Large increases in suspended sediment loads were necessary to increase the amount of sediment accumulating in the redd from the baseline scenario, with increases of 5\%, 10\% and $25 \%$, for sand, silt and clay, respectively. Increasing the sand input by $100 \%$ results in a $51 \%$ increase in the volume of redd infilled over the same time period (Fig. 5(a)). Furthermore, under this scenario, the baseline \% volume infilled accumulation quantity was reached 30 days earlier. This highlights the sensitivity of the SIDO-UK model to the larger sediment size class, with these particles taking up a larger volume within the redd and becoming more easily trapped. Completely removing the sand fraction sediment delivery to the reach resulted in $\sim 50 \%$ less sediment being retained in the egg zone.

The physical blockage of the inter-gravel pores by fine sediment resulted in the intra-gravel flow velocities decreasing (Fig. 5(b)). The doubling of sand input scenario caused the mean intergravel flow velocity to decrease by $24 \%$ from 59 to $45 \mathrm{~cm} \mathrm{~h}^{-1}$, while doubling of the silt and clay fractions resulted in $19 \%$ and $17 \%$ reductions, respectively. Removing all sand inputs to the study 
reach resulted in the average intra-gravel flow velocity increasing by $\sim 40 \%$ to $83 \mathrm{~cm} \mathrm{~h}^{-1}$, while the smaller particles had a much lower impact, with an average intra-gravel flow velocity of $65 \mathrm{~cm} \mathrm{~h}^{-1}$ and $60 \mathrm{~cm} \mathrm{~h}^{-1}$ for complete removal of silt and clay, respectively.

One of the factors controlling the dissolved oxygen concentration within the egg zone is the supply of oxygenated water which depends upon sufficient intra-gravel flow. Figure 5(c) shows the impact of changing the sediment loads upon the average dissolved oxygen concentration. Doubling the load of sand, silt and clay resulted in a $20 \%$ decrease from 7.2 to $5.7 \mathrm{mg} \mathrm{L}^{-1}, 18 \%$, and $15 \%$ decrease of average dissolved oxygen concentrations, respectively. Removing all the sand input caused a significant increase in average dissolved oxygen concentration of $\sim 30 \%$ to $9.4 \mathrm{mg} \mathrm{L}^{-1}$.

However, it is not the average abiotic conditions in the redd that control egg survival, but the actual conditions on each day of development (Reiser and White 1990). Therefore, it is the minimum values for the intra-gravel flow velocity and dissolved oxygen concentration that control the spawning success, as these factors may become limiting during the incubation period and result in egg death or sub-lethal effects. Different species of salmonid develop at different rates. The empirical relationships of Crisp (1981) are used for Atlantic Salmon, equation (1), and Brown Trout, equation (2) in SIDO-UK:

$$
\begin{aligned}
& \log _{10} D_{2}=\left[-2.6562 \log _{10}(T+11.0)\right]+5.1908 \\
& \log _{10} D_{2}=\left[-13.9306 \log _{10}(T+80.0)\right]+28.8392
\end{aligned}
$$

where $D_{2}=$ hatching time for $50 \%$ of eggs (days) and $T=$ temperature $\left({ }^{\circ} \mathrm{C}\right.$ ).

If both species are simulated under the same conditions (i.e. water temperature) then Brown Trout hatch first. Under the conditions used in these simulations, where water temperature remained constant, Brown Trout hatch on Day 76, while Atlantic Salmon hatch around Day 107. From Fig. 2 it is clear that the longer incubation period of Atlantic Salmon eggs makes them more susceptible to fine sediment intrusion as the storm period is from Day 60 to Day 90 . Figure 6 shows the abiotic conditions on the day of hatch for the two study species, which was when the redd was at its maximum infilled volume during the incubation period, meaning that the values for the intra-gravel flow velocity and dissolved oxygen were at their lowest. The redd was $21.9 \%$ and $22.5 \%$ infilled on the respective hatching days for Brown Trout and Atlantic Salmon. However, due to the shorter period between infilling starting and the day of hatch for Brown Trout, the intragravel flow was higher $\left(41.82 \mathrm{~cm} \mathrm{~h}^{-1}\right)$ when Brown Trout hatched than on day 107 when Atlantic Salmon hatched $\left(36.99 \mathrm{~cm} \mathrm{~h}^{-1}\right)$. There was a greater difference in the dissolved oxygen concentration at hatch. On Day 76, the dissolved oxygen concentration was $8.07 \mathrm{mg} \mathrm{L}^{-1}$, while on Day 107 it was $5.4 \mathrm{mg} \mathrm{L}^{-1}$. The EU Fisheries Directive (2006/44/EC) suggests that dissolved oxygen concentrations $>7 \mathrm{mg} \mathrm{L}^{-1}$ are required for successful salmonid populations to survive. It was estimated that $79 \%$ of the Brown Trout eggs would survive to hatch, while only $48 \%$ of the Atlantic Salmon eggs would be satisfied by the available oxygen and survive to hatch. This suggests that the shorter incubation time of Brown Trout eggs results in higher survival rates than for Atlantic Salmon eggs, even if a significant suspended sediment load occurs during this period as it takes time for the abiotic conditions in the redd to respond to the external pressure. Reductions in the sediment load show that the abiotic conditions are less limiting for Brown Trout eggs than for Atlantic Salmon eggs (Fig. 6).

\section{DISCUSSION}

The coincidence of egg incubation and sediment delivery events has consequences for achieving sustainable salmonid populations. However, there is some debate over the sediment accumulation process. Frostick et al. (1984) observed infilling occurring in a step-like nature in discrete events. This is because the accumulation rate is dependent upon the near bed concentration of suspended sediment, which is supply-limited. This is how sediment accumulation is represented within the SIDO-UK model, with the CBADJ parameter enhancing the concentration at the stream-gravel interface. Results from the model indicate redd infilling occurs in a step-like way which may be due to this process representation and the redd grid discretisation resolution. However, others have 


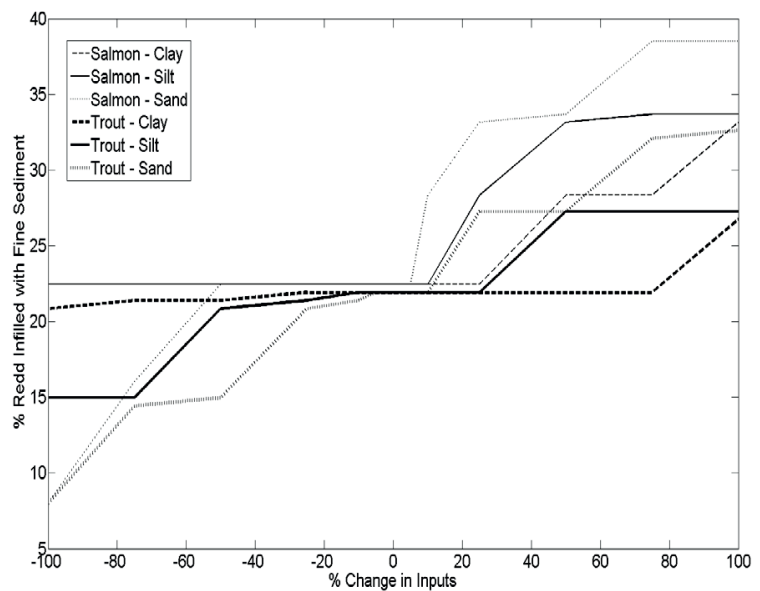

(a) \% redd infilled on day of hatch

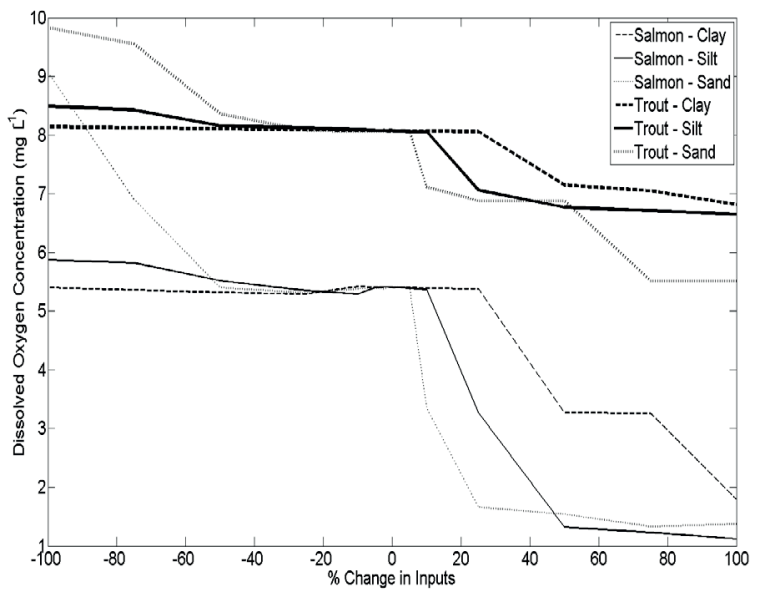

(c) Dissolved $\mathrm{O}_{2}$ level on day of hatch

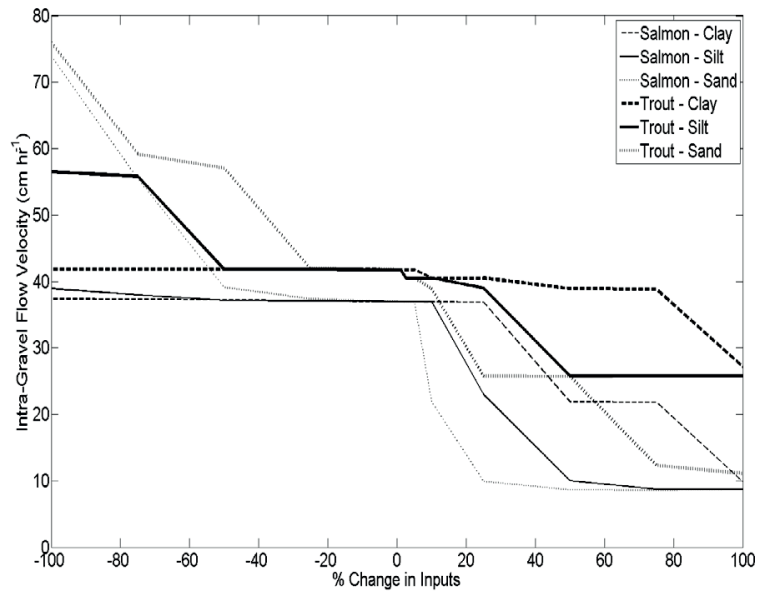

(b) Intra-gravel flow velocity on day of hatch

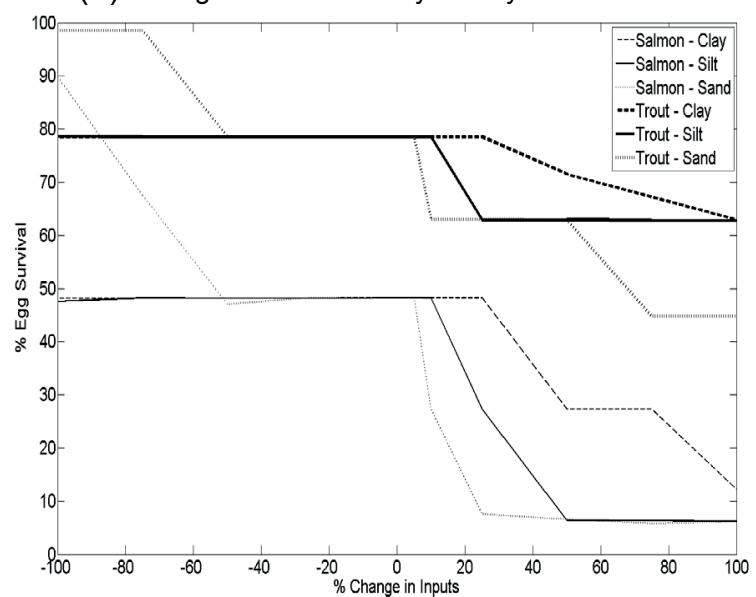

(d) Egg Survival rate

Fig. 6 Impact of changing sediment loads on: (a) infilling; (b) intra-gravel flow velocities; (c) dissolved oxygen concentrations; and (d) egg survival rate, on the day of hatch for Atlantic salmon and Brown trout.

proposed that gravel bed infilling with fine sediment is more of a continuous process (Zimmerman and Lapointe, 2005) with reductions in inter-gravel flow being observed after moderate sediment supply events. A third hypothesis is that infilling and accumulation follow a non-linear decline over time as the gravel fills up (Heywood and Walling, 2007), as the initial cut redd gravels are highly efficient at trapping fine sediment and this efficiency decreases as the redd fills up. Therefore, the magnitude and frequency of sediment delivery events is critical for egg incubation success, along with the stage of development of the egg when the storm events occur (Zimmerman and Lapointe, 2005).

\section{CONCLUSIONS}

The SIDO (Sediment Intrusion and Dissolved Oxygen)-UK model represents the process of sediment intrusion into salmonid redds, and simulates the resulting impacts on intra-gravel abiotic characteristics, including flow velocities and DO concentrations, which are key controls of fish egg development rates and survival. The model has been calibrated for the River Ithon using observed data for sediment accumulation within the gravel matrix collected by Greig et al. (2007) during the winter of 2002-2003. Here, the sensitivity of the SIDO-UK model to the input sedigraph has been tested by altering the loads of sand, silt and clay. The abiotic conditions within the egg zone have been found to be highly sensitive to the suspended sediment concentrations, particularly the sand component. It is hypothesised that sand particles reduce substrate permeability by blocking pores, which reduces the intra-gravel flow velocities and the supply of 
oxygen to the egg zone. The timing and magnitude of sediment delivery events have a significant impact upon how quickly the redd fills up and interstitial pores become clogged with fine sediment. Furthermore, the egg incubation time of different species has a significant effect upon survival rates. Brown Trout eggs hatch after a shorter incubation than Atlantic Salmon eggs. Therefore, the likelihood of the incubation period and sediment delivery events coinciding is much greater for Atlantic Salmon, meaning that eggs are exposed to sub-optimal and limiting conditions for longer and survival rates are lower. However, many ways in which fine sediment impacts upon fish egg survival, are not represented in SIDO-UK; e.g. the surface sealing caused by sand (Beschta and Jackson, 1979), the impacts of clay biofilms around eggs (Greig et al., 2005) and sediment-associated contaminants. The findings from this study, and the further application of SIDO-UK, may have significant implications for informing the management of sediment delivery to salmonid rivers (Collins and McGonigle, 2008; Collins et al., 2012).

Acknowledgements The authors gratefully acknowledge the funding provided by the Department for Environment, Food and Rural Affairs; Defra project WQ0128 - Extending the evidence base on the ecological impacts of fine sediment and developing a framework for targeting mitigation of agricultural sediment losses.

\section{REFERENCES}

Alonso, C.V., Theurer, F.D. \& Zachman, D.W. (1996) Sediment intrusion and dissolved oxygen transport model - SIDO. Technical Report No. 5, USDA-ARS National Sedimentation Laboratory, Oxford, Mississippi, USA. 232p.

Betchta, R.L. \& Jackson, W.L. (1979) The intrusion of fine sediments into a stable gravel bed. Journal of the Fisheries Research Board of Canada 36. 204-210.

Chapman, D.W. (1988) Critical review of variables used to define effects of fines in redds of large salmonids. Transactions of the American Fisheries Society 117, 1-21.

Crisp, D.T. (1981) A desk study of the relationship between temperature and hatching time for the eggs of five species of salmonid fishes. Freshwater Biology 11, 361-368.

Collins, A.L. \& McGonigle, D.F. (2008) Monitoring and modelling diffuse pollution from agriculture for policy support: UK and European experience. Environmental Science and Policy 11,97-101.

Collins, A.L., et al. (2012). Extending the evidence base on the ecological impacts of fine sediment and developing a framework for targeting mitigation of agricultural sediment losses. Final report to Defra, August 2012.

Cunjak, R., Prowse, T. \& Parrish, D. (1998) Atlantic salmon (Salmo salar) in winter: "the season of parr discontent". Canadian Journal of Fisheries and Aquatic Sciences 55(Suppl. 1), 161-180.

Frostick, L.E., Lucas, P.M. \& Reid, I. (1984) The infiltration of fine matrices into coarse-grained alluvial sediments and its implications for stratigraphical interpretation. Journal of the Geological Society of London, 141, 955-965.

Greig S. M., Sear DA, Smallman D, Carling PA. (2005) Impact of clay particles on cutaneous exchange of oxygen across the chorion of Atlantic salmon eggs. Journal of Fish Biology 66, 1681-1691.

Greig S.M., Sear, P.A. \& Carling, P.A. (2007) A field-based assessment of oxygen supply to incubating Atlantic salmon embryos. Hydrological Processes 21, 3087-3100.

Heywood, M.J.T. \& Walling, D.E. (2007) The sedimentation of salmonid spawning gravels in the Hampshire Avon catchment, UK: Implications for the dissolved oxygen content of intragravel water and embryo survival. Hydrological Processes 21, $770-788$.

Jones, J.I., et al. (2012a) The impact of fine sediment on macro-invertebrates. River Research and Applications 28(8), $1055-1071$.

Jones, J.I., et al. (2012b) The relationship between fine sediment and macrophytes in rivers. River Research and Applications, 28, $1000-1018$

Jones, J.I., et al. (2014) Interactions between diatoms and fine sediment. Hydrological Processes 28, 1226-1237.

Kemp, P., et al. (2011). The impacts of fine sediments on freshwater fish. Hydrological Processes 25, $1800-1821$.

Pattison, I., et al. (in review) Modelling the impact of fine sediment accumulation on the oxygen supply to incubating salmonids.

Reiser, D.W. \& R.G. White. 1990. Effects of streamflow reduction on Chinook salmon egg incubation and fry quality. Rivers $1(2), 110-118$.

Remo, J.W.F., Pinter, N. \& Heine, R. (2009) The use of retro and scenario modelling to assess effects of $100+$ years river of engineering and land cover change on Middle and Lower Mississippi River flood stages. Journal of Hydrology 376, $403-416$.

Salomons, W. \& Forstner, U. (1984) Metals in the Hydrocycle. Berlin, Springer Verlag.

Sear, D.A., et al. (2008) The significance and mechanics of fine sediment infiltration and accumulation in gravel spawning beds. In: Salmonid Spawning Habitat in Rivers; Physical controls, biological responses and approaches to remediation. (ed. by Sear, D.A. \& DeVries, P.). AFS, Bethesda, Maryland, USA, 1491-174.

Theurer, F.D. \& Theurer, K.M. (1986) Draft Tucannon River offsite study: dissolved oxygen consumption. USDA unpublished draft report; $28 \mathrm{pp}$.

Zimmerman, A.E. \& Lapointe, M. (2005) Intragranular flow velocity through salmonid redds: Sensitivity to fines infiltration from low intensity sediment transport events. River Research and Applications 21, 865-888. 